\title{
THE USE OF PENICILLIN IN THE LOCAL TREATMENT OF PNEUMOCOCCAL EMPYEMA ${ }^{1,2}$
}

\author{
By WILLIAM S. TILLETT, JAMES E. MCCORMACK, AND \\ MARGARET J. CAMBIER \\ (From the Department of Medicine of New York University College of Medicine and the \\ Third Medical Division of Bellevue Hospital, New York City)
}

(Received for publication January 18, 1945)

In a previous article (1), results were presented concerning the use of penicillin, injected intrapleurally, in the treatment of pneumococcal empyema. The method of treatment, its effect on the clinical course of the disease, and the final outcome were described in 8 patients. In 7 of them, the infection was eradicated and the suppurative process cleared completely without requiring more than repeated medical thoracenteses for drainage. In 1 patient, a child of 2 years of age, surgical drainage by rib resection was employed when a relapse of the infection occurred shortly after cessation of the first injections of penicillin.

It is the purpose of the present article to supplement the previous report by adding the results obtained from 13 additional cases of pneumococcal empyema, which have been successfully treated in a similar manner.

Pertinent features of the recent cases, hitherto unreported, will be described in the text of this article and, in addition, data from the total of 21 cases will be consolidated and discussed on the basis of the larger experience.

Patients used for study. In 19 of the patients, the empyema occurred in a typical manner as a complication of lobar pneumonia. In the remaining 2 , the history suggested that the empyema had developed from a bronchopleural fistula which occurred in association with an acute pneumonitis.

Two of the patients had long-standing pulmo-

\footnotetext{
1 This investigation was aided in part by the Commission on Pneumonia, Board for the Investigation and Control of Influenza and Other Epidemic Diseases in the Army, Preventive Medicine Service, Office of the Surgeon General, U. S. Army.

2 The penicillin was provided by the Office of Scientific Research and Development from supplies assigned by the Committee on Medical Research for clinical investigations recommended by the Committee on Chemotherapeutic and Other Agents of the National Research Council.
}

nary tuberculosis on which pneumonia and empyema were superimposed.

Only 2 of the patients came under our observation during the acute pneumonic phase of the infection. The remainder were transferred from other wards of Bellevue Hospital or elsewhere after the pneumonia had subsided and empyema had developed. The period in the infection at which penicillin therapy was first instituted varied from the 4th to the 48th day.

Neither intramuscular nor intravenous injections of penicillin were used in the treatment except in the 2 patients who had acute pneumonia and bacteremia at the time of admission. After the initial phase of active pneumonia was controlled by intravenous injections of penicillin, subsequent treatment was limited to intrapleural injections.

Selected data on the 21 patients are given in Table I. The patients who were described in a previous article (1) are designated by $P$ (1P, $2 \mathrm{P}, 3 \mathrm{P}, 10 \mathrm{P}, 11 \mathrm{P}, 12 \mathrm{P}, 17 \mathrm{P}$, and $19 \mathrm{P})$. The recent cases are designated by numbers only $(4,5$, $6,7,8,9,13,14,15,16,18,20$, and 21 ).

The discussions which follow center around the data presented in Table I.

The ages of the patients ranged from 2 to 71 years. Three of them, ages 2,8 , and 11 years, respectively, were treated on the Pediatric Service. The immediate response to treatment and the degree of ultimate clearing of the lesion were comparable in each of the age groups.

With regard to sex, it may be noted from Table I that there were 16 males and 5 females. The preponderance of one sex suggests an increased frequency of empyema among males although all of the factors that might account for the uneven occurrence have not been analyzed.

Among the serological types of pneumococci responsible for the empyemas, Type I infections (6 
cases) were the most frequent. The incidence is in consonance with previous reports that empyema is found as a complication of Type I pneumococcus pneumonia more often than in connection with other types.

In 14 (66 per cent) of the cases, pneumococci Types I to VIII, were found to be the causative agents. From the remaining 7 cases, pneumococci of the higher types ranging from Types XI to XX were identified.

The figures listed in Table I under Day of disease (Pneumonia) refer to the interval between the onset of the primary pneumonia from which empyema developed and the first thoracentesis at which penicillin was introduced. The data as given serve to indicate the approximate duration of infection before local therapy was instituted.

It may be noted from Table I that cases were first seen both early and late in the infection. However, there appeared to be no uniform relationship between the degree of effectiveness of treatment and the duration of infection before therapy was instituted. The cases treated late responded in a satisfactory manner and required no greater amount of treatment than early cases.

Mode of treatment. The solutions of penicillin were prepared with isotonic salt solution usually in the ratio of 1000 units per $\mathrm{ml}$. When the amount of exudate removed by aspiration was insufficient to permit the introduction of the proper quantity of the solution, the planned dose of penicillin units was maintained by decreasing the amount of physiological salt solution used as solvent.

The 3 factors in the intrapleural therapy with penicillin which have received special consideration were the amount of penicillin per dose, frequency of injections, and duration of treatment.

Individual dosages in different cases have varied from as little as 5,000 units in the earliest cases to 100,000 units in others. Without elaborating unnecessary details, it has been concluded that less than 20,000 units per dose is liable to be insufficient and it was previously suggested (1) that 30,000 to 40,000 units appeared satisfactory. More recently, other cases have received 50,000 and 100,000 units per dose in the initial series of injections. The rate of clearing of the exudate and the speed of recuperation were not, however, significantly different from that of other cases receiving the lesser amounts that were recommended. Although the optimal dosage for individual cases may vary, in view of the fact, as previously demonstrated (1), that penicillin is irritating locally in the pleural cavity, unnecessarily large doses may contribute to the transient reaccumulations of exudate and possibly delay final complete clearing without being more effective in eradicating the infection unless the extent of the pleural involvement is unusually large.

With respect to the frequency of intrapleural injections, in the previous study it was found, among the patients tested, that penicillin remained active for at least 48 hours after the initial injection. It was concluded, therefore, that in cases of pneumococcal infection no demonstrable advantage was derived from repetitions of injections oftener than on alternate days.

The number of repetitions of injections constituted the third factor in the therapeutic problem.

In 2 patients (M. W. (6) and M. B. (11P) of Table I) who had small empyemal pockets, only one injection was required, and in a third patient (A. Mc. (1P) of Table I), 2 doses were found to be adequate.

In the remaining 17 patients, the initial treatment consisted of 3 to 5 injections and in 11 of them, the first series of injections proved sufficient to effect complete eradication of the infection. In 7 others, however, relapses of the infection occurred when treatment was suspended, as evidenced by a return of organisms demonstrable in the pus and by a rise in fever.

The significant immediate effect of penicillin in all of the patients was regularly evident by the fact that in samples of exudate removed on the day following the first injection, the pneumococci were represented by disintegrating forms seen in direct smears, and cultures of the pus were in most instances sterile. Similar bacteriological observations on the second day failed to reveal viable or cultivable organisms.

However, the initial disappearance of pneumococci from the free pleural exudate occurred as promptly in the 7 instances of relapse as it did in the 14 other patients in whom the first series of injections proved adequate. Consequently, the arbitrary selection of the point at which therapy could be suspended has remained on an empirical basis since no specific clinical findings in the pa- 
TABLE I

Data on patients with pneumococcal empyema treated by intrapleural injections of penicillin

\begin{tabular}{|c|c|c|c|c|c|c|c|c|c|c|c|}
\hline \multirow{2}{*}{ Patient } & \multirow{2}{*}{ Age } & \multirow{2}{*}{ Sex } & \multirow{2}{*}{$\begin{array}{l}\text { Type of } \\
\text { pneumo- } \\
\text { coccus }\end{array}$} & \multirow{2}{*}{$\begin{array}{c}\text { Day } \\
\text { of } \\
\text { disease } \\
\text { (pneu- } \\
\text { monia) }\end{array}$} & \multicolumn{3}{|c|}{ Intrapleural penicillin } & \multirow{2}{*}{$\begin{array}{c}\text { No. of } \\
\text { aspira- } \\
\text { tions }\end{array}$} & \multirow{2}{*}{$\begin{array}{c}\text { Days } \\
\text { between } \\
\text { 1st and } \\
\text { last aspi- } \\
\text { ration }\end{array}$} & \multirow{2}{*}{$\begin{array}{c}\text { Days in } \\
\text { hospital } \\
\text { (empyema) }\end{array}$} & \multirow{2}{*}{ Relapses } \\
\hline & & & & & $\begin{array}{c}\text { No. of } \\
\text { injections }\end{array}$ & $\begin{array}{l}\text { Amount per } \\
\text { dose, 1000's }\end{array}$ & $\begin{array}{l}\text { Total, } \\
\text { 1000's }\end{array}$ & & & & \\
\hline A. Mc. (1P) & $\cdot 57$ & $\mathbf{M}$ & I & 33 & 2 & 40 & 80 & 5 & 21 & 42 & None \\
\hline J. D. (2P) & 58 & $\mathbf{M}$ & I & 10 & 3 & 25 & 75 & 10 . & 42 & 52 & None \\
\hline E. F. (3P) & 11 & $\mathrm{~F}$ & I & 34 & 3 & 25 & 75 & 3 & 13 & 21 & None \\
\hline R. C. (4) & 8 & $\mathbf{M}$ & I & 48 & 4 & 30 & 120 & 6 & 21 & See note & None \\
\hline T. C. (5) & 45 & $\mathbf{M}$ & I & 23 & $\begin{array}{r}93 \\
6\end{array}$ & $\begin{array}{c}30 \\
30-100\end{array}$ & 470 & 10 & 21 & 50 & 1 \\
\hline M. W. (6) & 50 & $\mathbf{M}$ & I & 35 & 1 & 25 & 25 & 2 & 7 & 17 & None \\
\hline E. W. (7) & 49 & $\mathbf{M}$ & II & 22 & $\begin{array}{r}43 \\
1\end{array}$ & $\begin{array}{l}30 \\
50\end{array}$ & 140 & 6 & 14 & 28 & None \\
\hline J. O'M. (8) & 45 & $\mathbf{M}$ & II & 28 & 7 & 50 & 350 & 10 & 44 & 47 & 1 \\
\hline H. S. (9) & 59 & $\mathbf{M}$ & II & 15 & $\begin{array}{r}74 \\
3\end{array}$ & $\begin{array}{r}50 \\
100\end{array}$ & 500 & 8 & 18 & 50 & 1 \\
\hline M. L. (10P) & 42 & $\mathbf{F}$ & $\mathrm{V}$ & 7 & $\begin{array}{r}93 \\
6\end{array}$ & $\begin{array}{r}5-10 \\
20-30\end{array}$ & . 155 & 16 & 44 & 79 & 3 \\
\hline M. B. (11P) & 33 & $\mathbf{M}$ & $\mathrm{V}$ & 4 & 1 & 40 & 40 & 4 & 19 & 25 & None \\
\hline E. M. (12P) & 35 & $\mathbf{M}$ & VIII & 15 & 5 & $15-25$ & 100 & 8 & 47 & 62 & $\left(\begin{array}{l}\text { None } \\
\text { (3 } \text { pockets) }\end{array}\right.$ \\
\hline R. E. (13) & 37 & $\mathbf{M}$ & VIII & 16 & 3 & 50 & 150 & 12 & 32 & 34 & None \\
\hline G. Q. (14) & 49 & $\mathbf{M}$ & VIII & 12 & $\begin{array}{r}98 \\
1 \\
\end{array}$ & $\begin{array}{r}50 \\
100 \\
\end{array}$ & 400 & 11 & 32 & 42 & 1 \\
\hline R. M. (15) & 23 & $F$ & XI & 25 & 5 & 30 & 150 & $\begin{array}{c}\text { Tbc. } \\
\text { com }\end{array}$ & $\begin{array}{l}\text { jee case } \\
\text { nent. }\end{array}$ & 45 & None \\
\hline L. T. (16) & 38 & $\mathbf{F}$ & XV & 11 & 4 & 50 & 200 & 6 & 23 & 43 & None \\
\hline M. J. (17P) & 2 & $\mathbf{M}$ & XVI & 18 & 3 & 5-15 & 30 & 3 & Surgical & 131 & 1 \\
\hline G. B. (18) & 22 & $\mathbf{M}$ & XVIII & 6 & 4 & 50 & 200 & $\begin{array}{l}\text { Tbc. } \\
\text { com }\end{array}$ & $\begin{array}{l}\text { jee case } \\
\text { nent. }\end{array}$ & 54 & None \\
\hline C. G. (19P) & 27 & $F$ & XIX & 45 & 3 & 30 & 90 & 3 & 11 & 26 & 1 \\
\hline A. S. (20) & 50 & $\mathbf{M}$ & XIX & 11 & 3 & 30 & 90 & .3 & 8 & 33 & None \\
\hline F. E. (21) & 71 & $\mathbf{M}$ & $\mathrm{XX}$ & 26 & $\begin{array}{r}43 \\
1\end{array}$ & $\begin{array}{r}100 \\
50\end{array}$ & 350 & 7 & 18 & 40 & None \\
\hline
\end{tabular}

tients or laboratory examinations of the exudate have indicated the liability of recurrence of the infection. Further studies of this point are now in progress.

When the relapses occurred, treatment was reinstituted in 6 of the patients. Not infrequently, a larger amount of penicillin consisting of 50,000 or even 100,000 units per dose was injected. Irrespective of the size of the doses, the infection diminished in each instance as promptly as it had done after the first series of injections and the return to treatment following the first relapse resulted in permanent cure.

The occurrence of 3 relapses in one patient (M. L. (10P) of Table I) was obviously referable to the insufficiency of the early doses. It is interesting to note, however, that her ultimate recovery was as complete as that of any of the other 
patients who were successfully treated in shorter periods of time. (X-ray photographs of the case were reproduced in the previous article (1).)

Among the 7 patients in whom recurrences of the infection developed, viable pneumococci became demonstrable between the fourth and seventh day after the last introduction of penicillin. The maintenance of sterility, therefore, as determined by direct examination of pus and by cultures, for as long as 8 days after cessation of therapy, has, in the present series of cases, been found to be a reliable indication of the complete eradication of the infecting organisms.

The data with respect to the number of repeated injections of penicillin that were employed may be summarized as follows: Among the 14 patients who recovered following the initial treatment,

2 received 1 injection of penicillin

1 received 2 injections of penicillin

4 received 3 injections of penicillin

5 received 4 injections of penicillin

2 received 5 injections of penicillin.

Of the 7 patients who had relapses of the infection-excluding 2 that received only 5,000 units per dose at the beginning of treatment-among the remaining 5, 3 received an initial series of 3 injections, and 2 received an initial series of 4 injections.

When the first period of therapy proved insufficient, the number of treatments that were subsequently employed ranged from 3 to 6 injections according to subjective estimates of individual factors presented by different cases.

Number of aspirations. The total number of aspirations listed in Table I refers to thoracenteses that were performed both during and after treatment. Each injection of penicillin was preceded by removal of as much exudate as possible. After penicillin therapy was discontinued, subsequent aspirations were carried out as indicated by the physical state of the patient and $\mathrm{x}$-ray examinations of the chest.

The number of post-therapeutic aspirations of the chest varied from none in 4 cases to a maximum of 8 and 9 , respectively, in 2 of the cases. The average for all the group ranged from 3 to 4 .

Time required to effect recovery. Because of the gradual nature of the resolution of the lesion, the selection of a period representing the termina- tion of the resolving process has proved to be unavoidably vague. However, in order to gain some information with respect to the duration of the illness under penicillin therapy, the first unsuccessful attempt at thoracentesis was selected as most appropriately indicating the essential endpoint and the intervals between the first and last successful aspirations are listed in Table I. Utilizing the figures given in the column, the average duration of illness was found to be 24 days. The shortest periods were 7 and 8 days (M. W. (6) and A. S. (20) of Table I). The longest periods, 44,44 , and 47 days were required by 2 patients (J. O'M. (8) and M. L. (10P) of Table I) who had relapses of the infection and by one patient (E. M. (12P) of Table I) who developed 3 separate pockets.

Among the patients who did not have relapses, the average time was approximately 19 days.

There is also listed in Table I the number of days that the patients remained in the hospital after treatment was instituted. Since the patients were not infrequently kept in the hospital for purposes of observation particularly with reference to the rate of clearing and possibility of recurrence or the development of chronic empyema, the duration of their stay did not represent the period requiring hospital care. Even before the period of repeated aspirations ceased, they were ambulatory and were gaining weight. A low grade fever, $99^{\circ}$ to $100^{\circ} \mathrm{F}$., and slight leukocytosis, 9,000 to 10,000 W.B.C. per c.mm. were the chief general abnormal findings.

The evolution of the local pleural lesion followed an interesting course. The discrepancy between the relative slowness of the rate of disappearance of the exudate as contrasted with the rapidity of the sterilization of the pus bacteriologically, has been consistently observed. During the early stages of treatment, as previously noted, the rapid disintegration of the organisms and their disappearance constituted the most noticeable changes observed in samples of exudate obtained at daily intervals. During the later stages of the aspirations after the instillations of penicillin had ceased, the microscopical appearance of specimens of the exudate was characterized by a decrease in the number of leukocytes and changes in their morphology from the characteristic polymorphonuclear structure to swollen forms of disintegrat- 
ing cells that stained poorly. Finally, there was almost complete absence of formed cellular elements. During the latter period, the character of the exudate did not, however, usually change to thin serous material but remained, in nıost instances, thick even during the period in which the lesion was regressing and the pleural shadow as seen by $\mathrm{x}$-ray examination was decreasing in size and lessening in density.

Irrigation of the empyemal pockets with isotonic salt solution has been employed in an effort to hasten final clearing. In some instances, the procedure appeared to be advantageous and in others, the course was not significantly altered. In several of the patients, reaccummulations of exudate took place in the absence of any demonstable bacteria and at a time when the general clinical condition of the patient was progressing in a satisfactory manner. The extent, therefore, to which repeated aspirations promote the ultimate clearing of the lesion is not clearly established. In this connection, the course of patient R. E. (No. 13 in Table I), which is given in "Comments on Individual Cases," is interesting to note.

By repeated x-ray examinations, both during hospitalization and after discharge, additional observations have been made on the progressive changes in the disease process that have occurred after the accumulation of free fluid had ceased and until the maximal degree of clearing appeared to be established.

Since the final outcome with respect to the anatomical and physiological state of the affected side of the thorax is the most important factor in estimating the value of therapy employed, a reduplication of pre-treatment $x$-ray photographs and also of the final examination are given for 7 of the recent series of 13 cases. (The 2 cases with tuberculosis are excluded since the tuberculosis involvement which has persisted overshadows the other changes.) Similar photographs of 6 of the earlier cases were presented in the previous article (1).

An examination of the photographs reveals that the final status in most of the cases consists of a partial flattening of the convex contour of the diaphragm and the extreme lateral corner of the pleural space is adherent. A diffuse thickening of the whole area of pleural involvement is not generally evident, nor is there any decrease in the intercostal spaces of the affected side.

On physical examinations made at the time of the $\mathrm{x}$-ray photographs, there was no appreciable limitation of expansion nor was deformity of the affected side noticeable. By fluoroscopy, the diaphragmatic excursions of the side previously involved were found in some of the cases to be limited but in none of them was the movement rigidly fixed. In a few instances, determinations of vital capacity were made and found to be normal.

It may be concluded, therefore, that the treatment which was employed has permitted the lungs of the affected side to return to a functional level that is essentially normal and that anatomically the thorax of the affected side is left with an amount of residual fibrosis that appears by $\mathrm{x}$-ray examination to be considerably less than the area of the original empyemal involvement.

In a recent article, other investigators (2) have described the results which they obtained by the use of penicillin in acute empyema. In 7 of their cases, pneumococci were the causative bacteria, and streptococci of several varieties (hemolytic, non-hemolytic, anaerobic, and micro-aerophilic) were responsible for the infections in the others. Although a number of their patients recovered completely in an uneventful fashion, they concluded that "aspiration alone often leaves a thickened pleura and a rigid chest wall with the consequent disabilities of reduced vital capacity, fibrosis, and risk of recurrent pulmonary infection."

The patients described in this article have not exhibited the serious residual defects described above. Chronic empyema has not developed and convalescence has not been characterized by any of the debilitating effects of protracted infection. It should be emphasized that the present group of cases has been limited to pneumococcal infections. In a subsequent report, our experience with empyemata due to other species of pathogenic bacteria will be presented. Among the different types of suppurative pleurisy, differences in the character of the underlying lesion on which the empyemata were superimposed and variations in the necrotizing and other pathogenic properties of the several species of infecting organisms have been found to constitute factors that need to be 

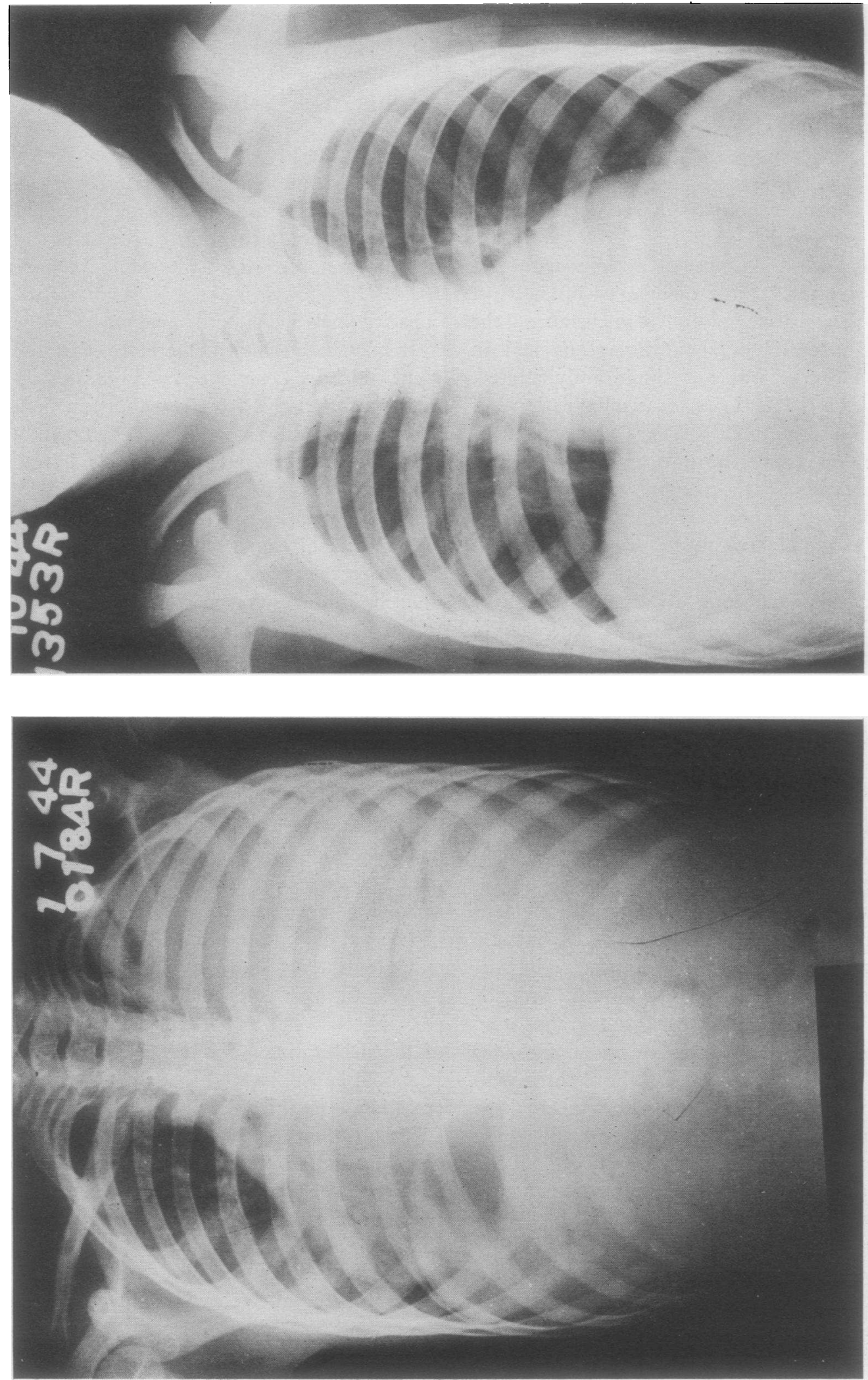

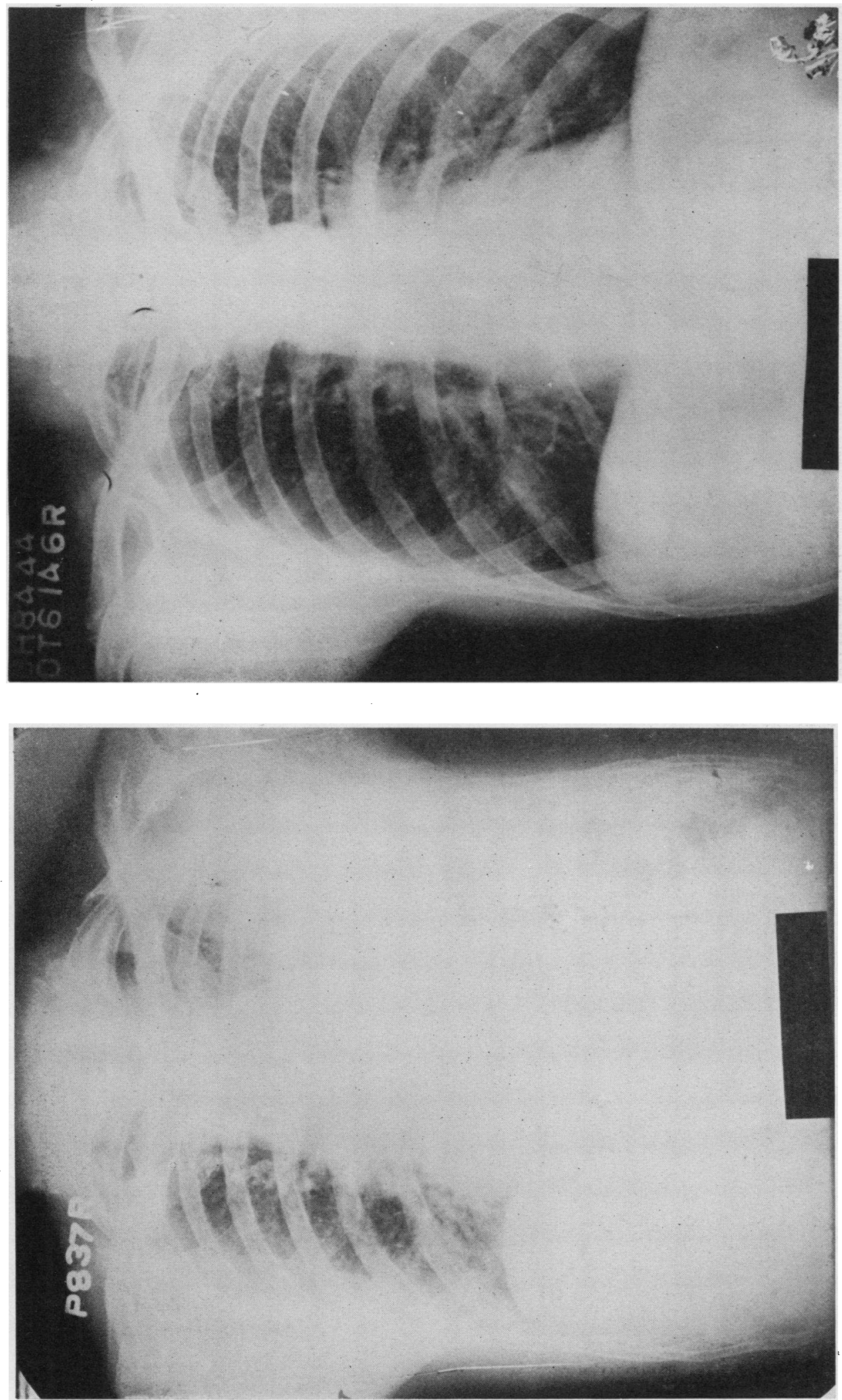

$n$
2
0
0
0
0
0
0
0
0
0
0
0
0 

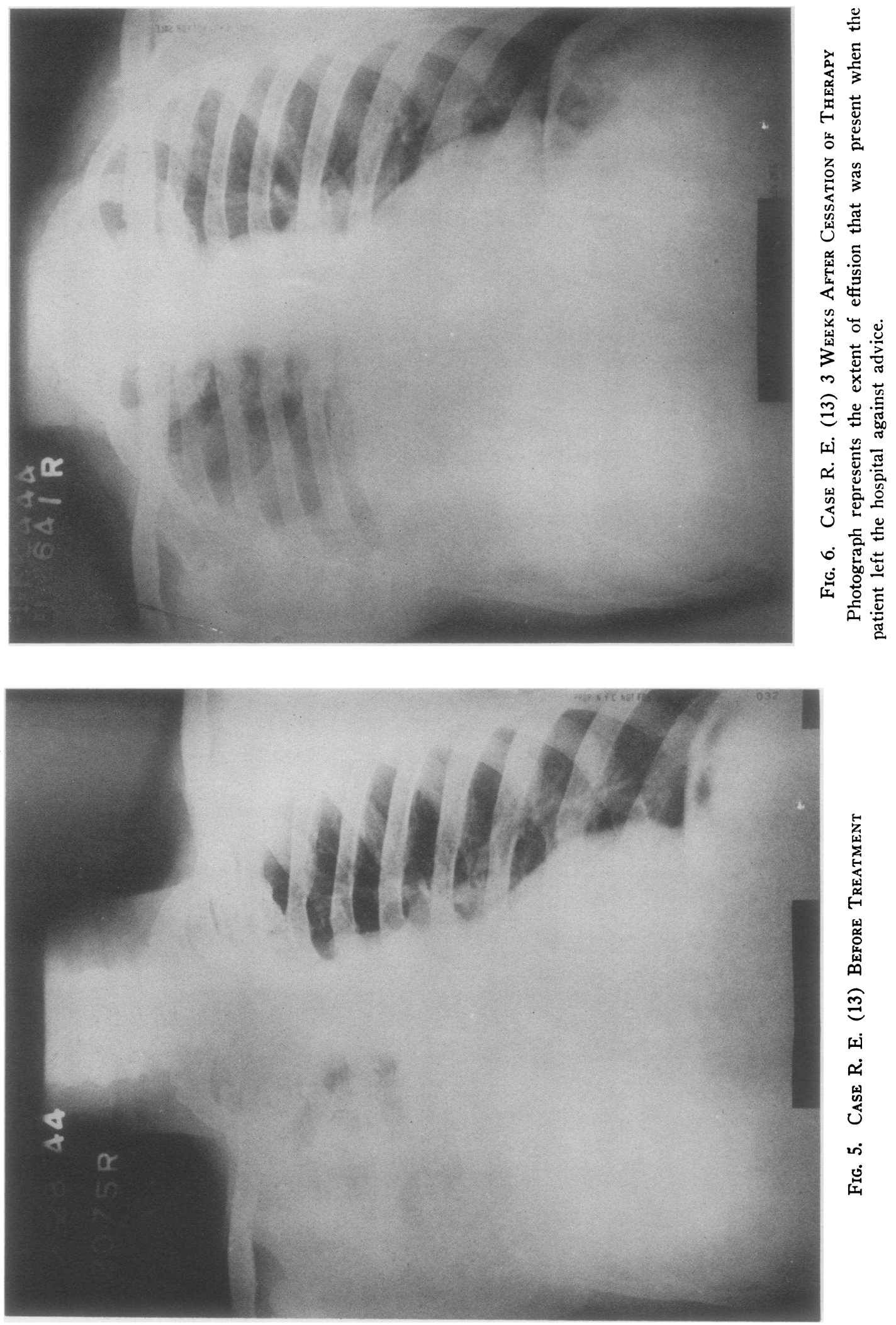

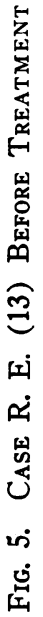




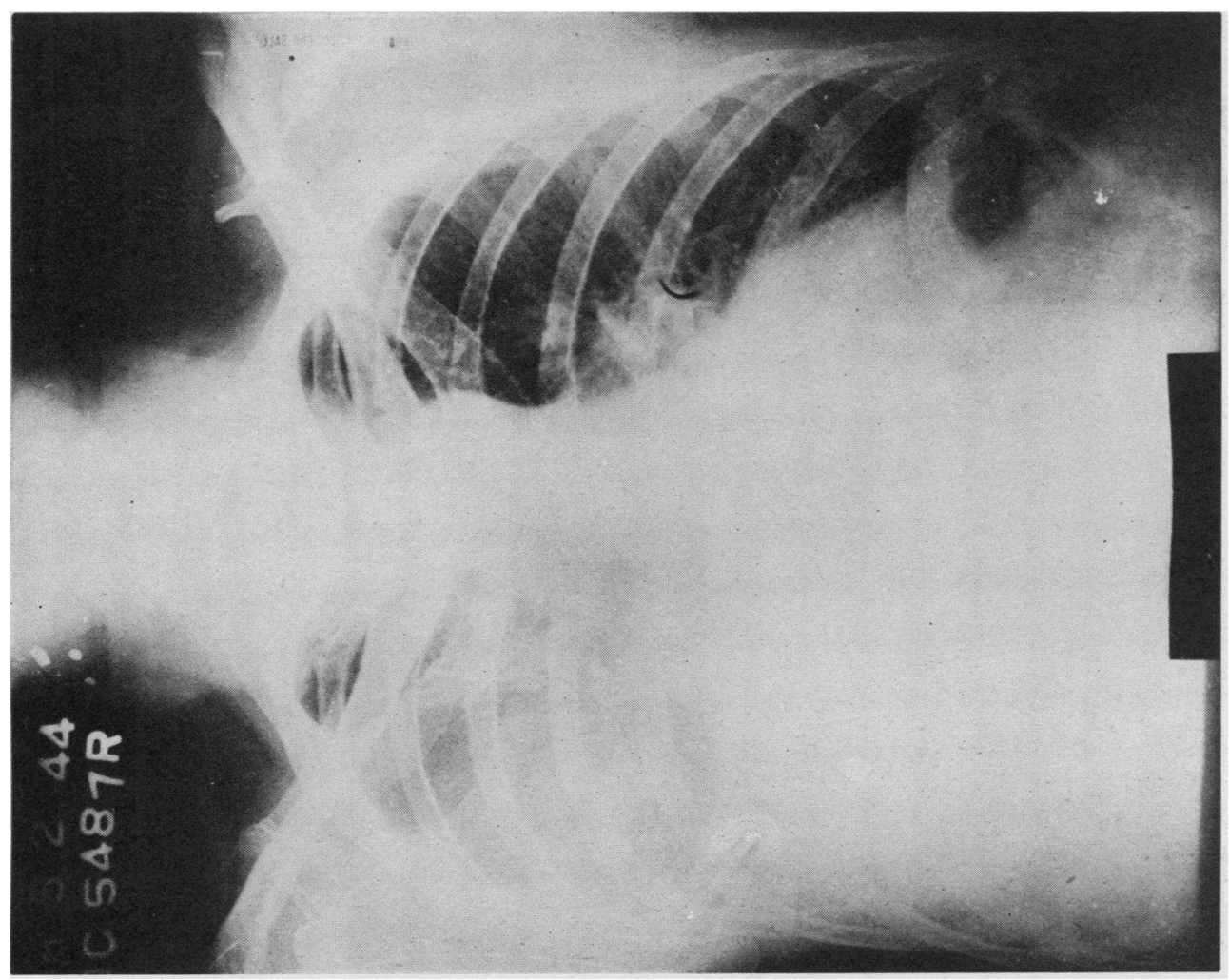

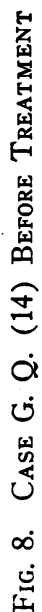

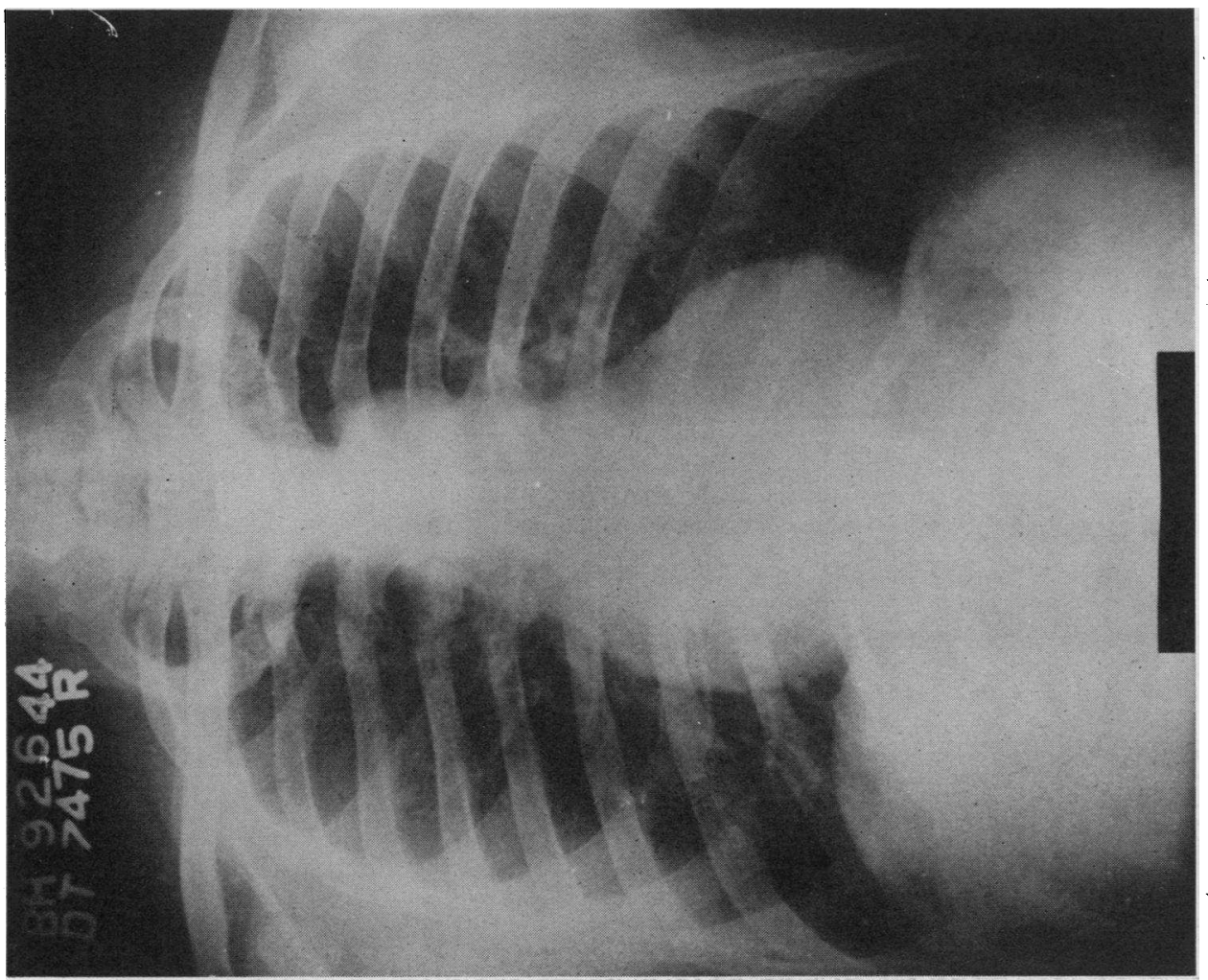

列

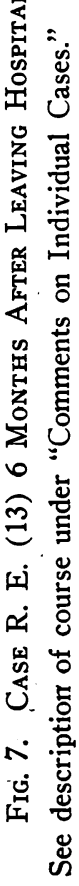




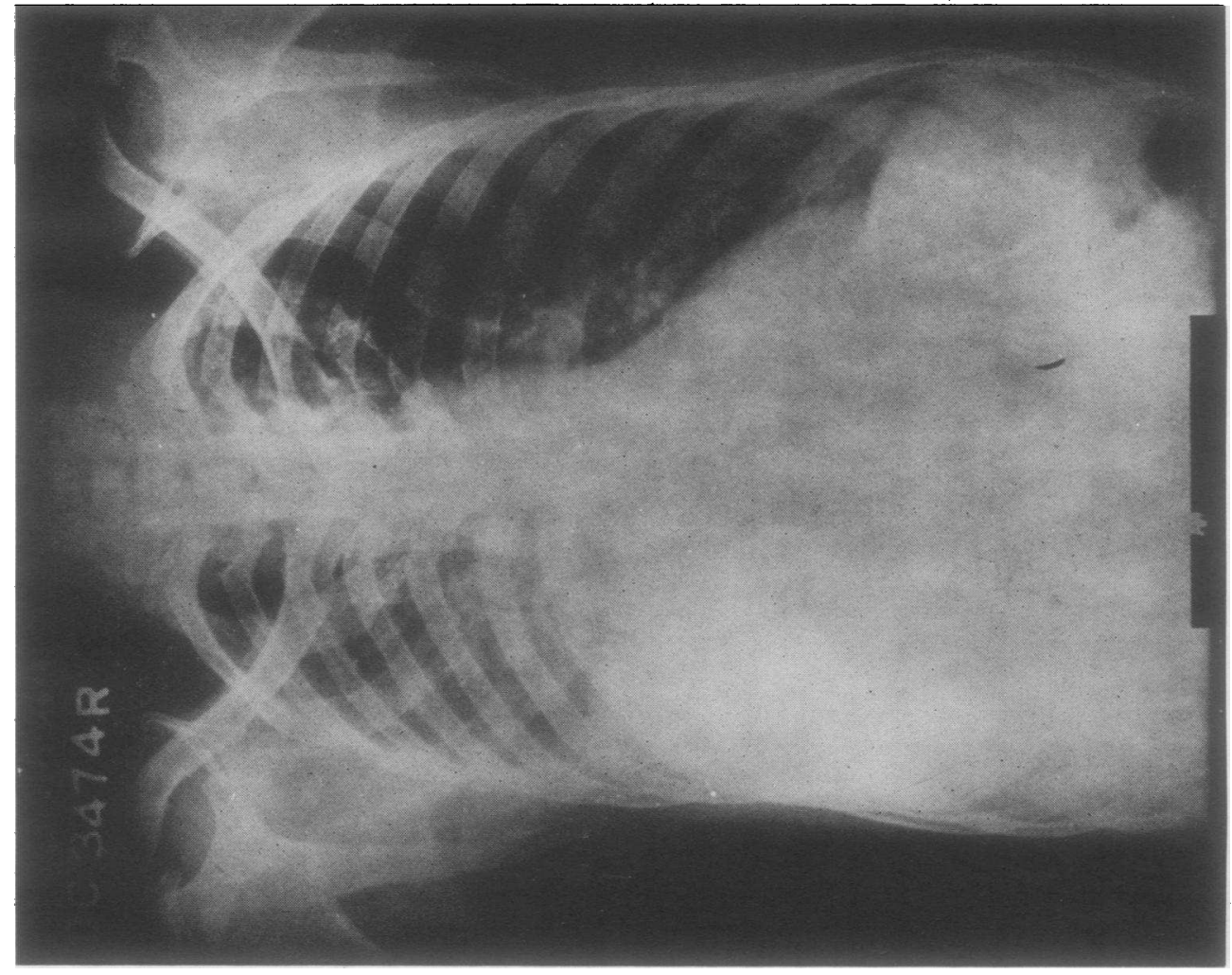

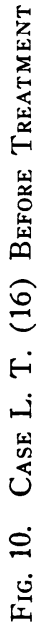

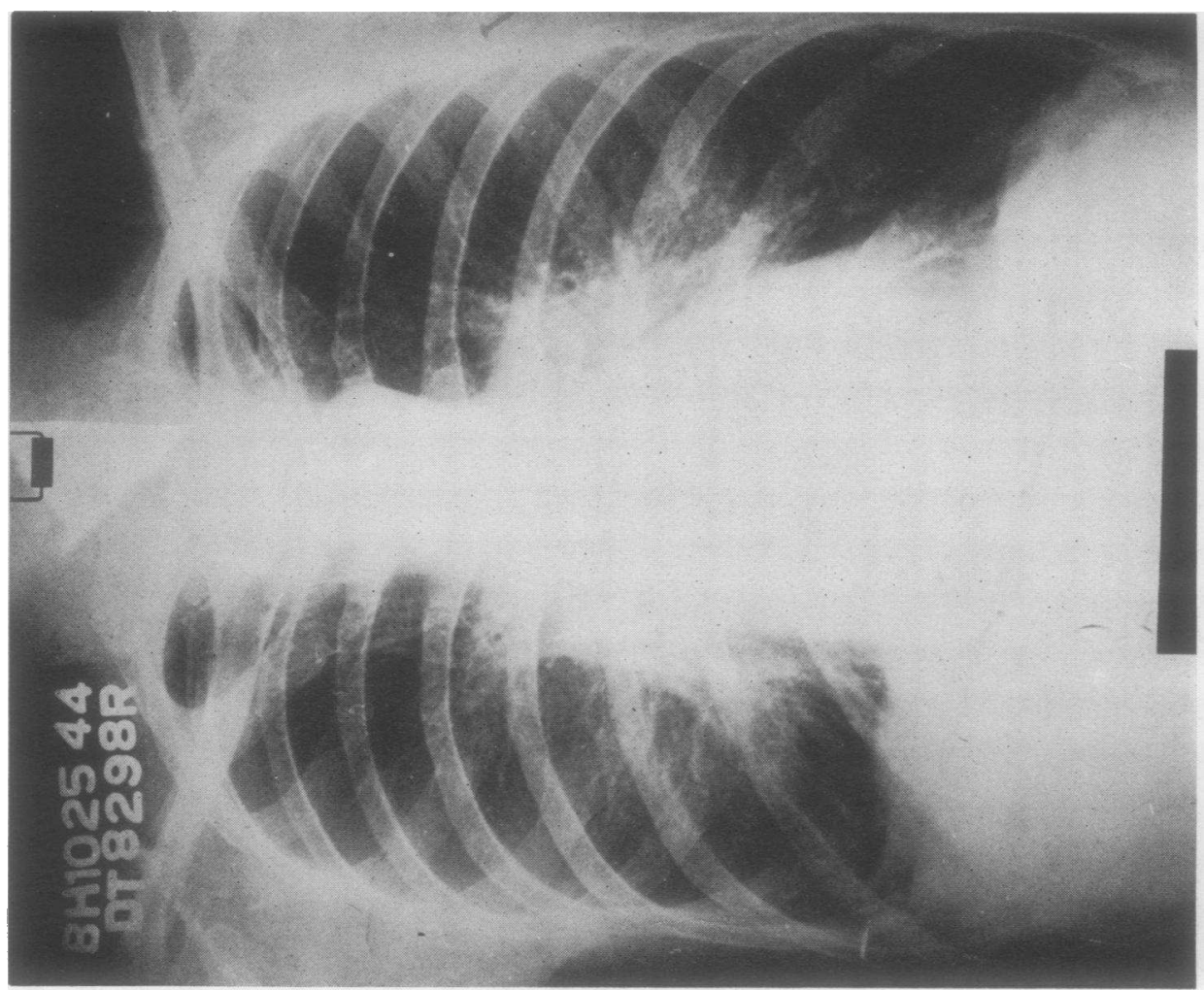

矛

貾

密苍

空

跑

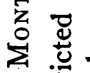

+ 要

$\widehat{\Xi}$

常

ब

ن

कृ

U.

$\sigma$ 焉

ن

齿 至的 

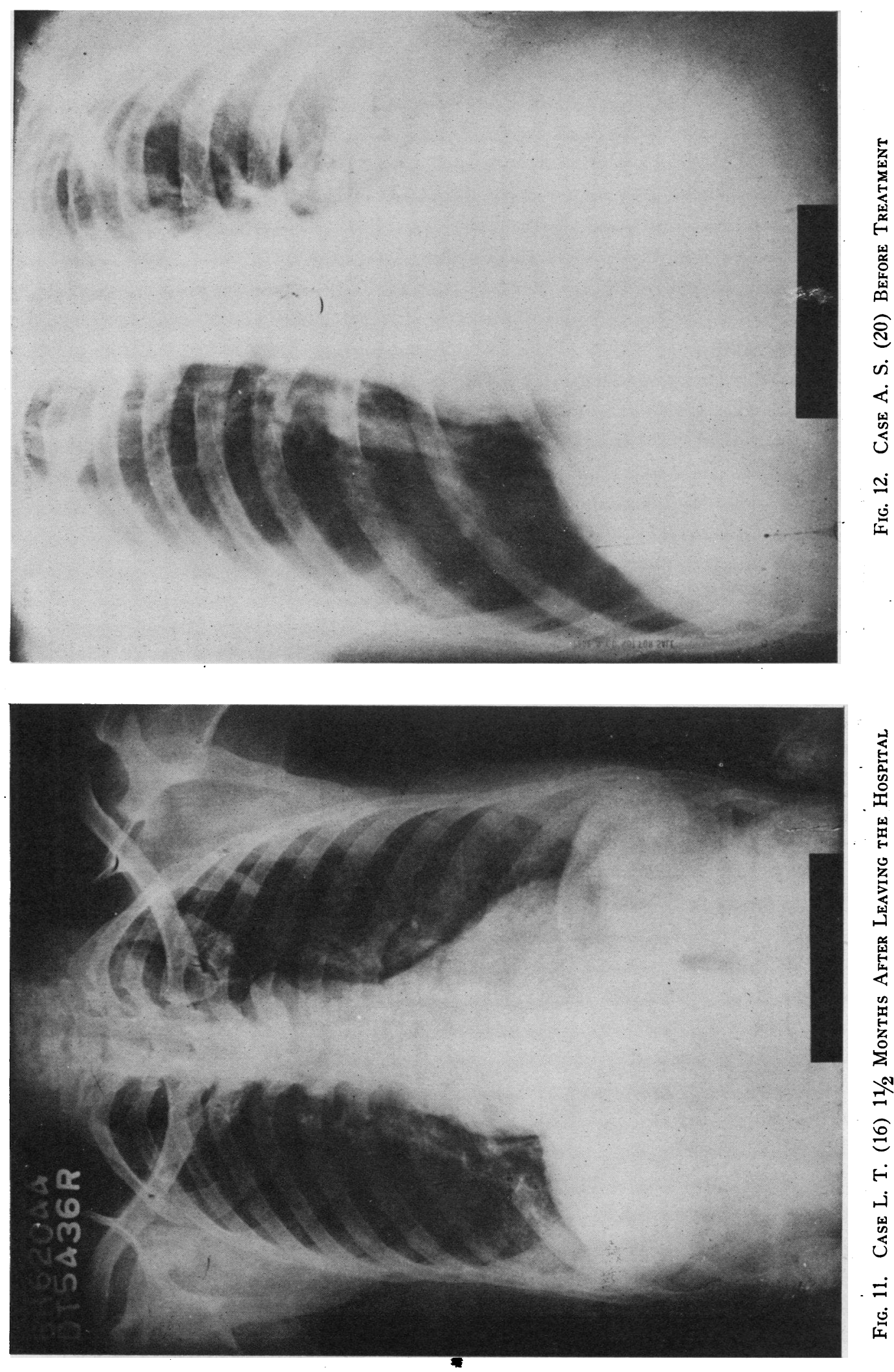

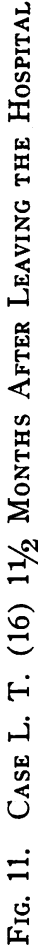



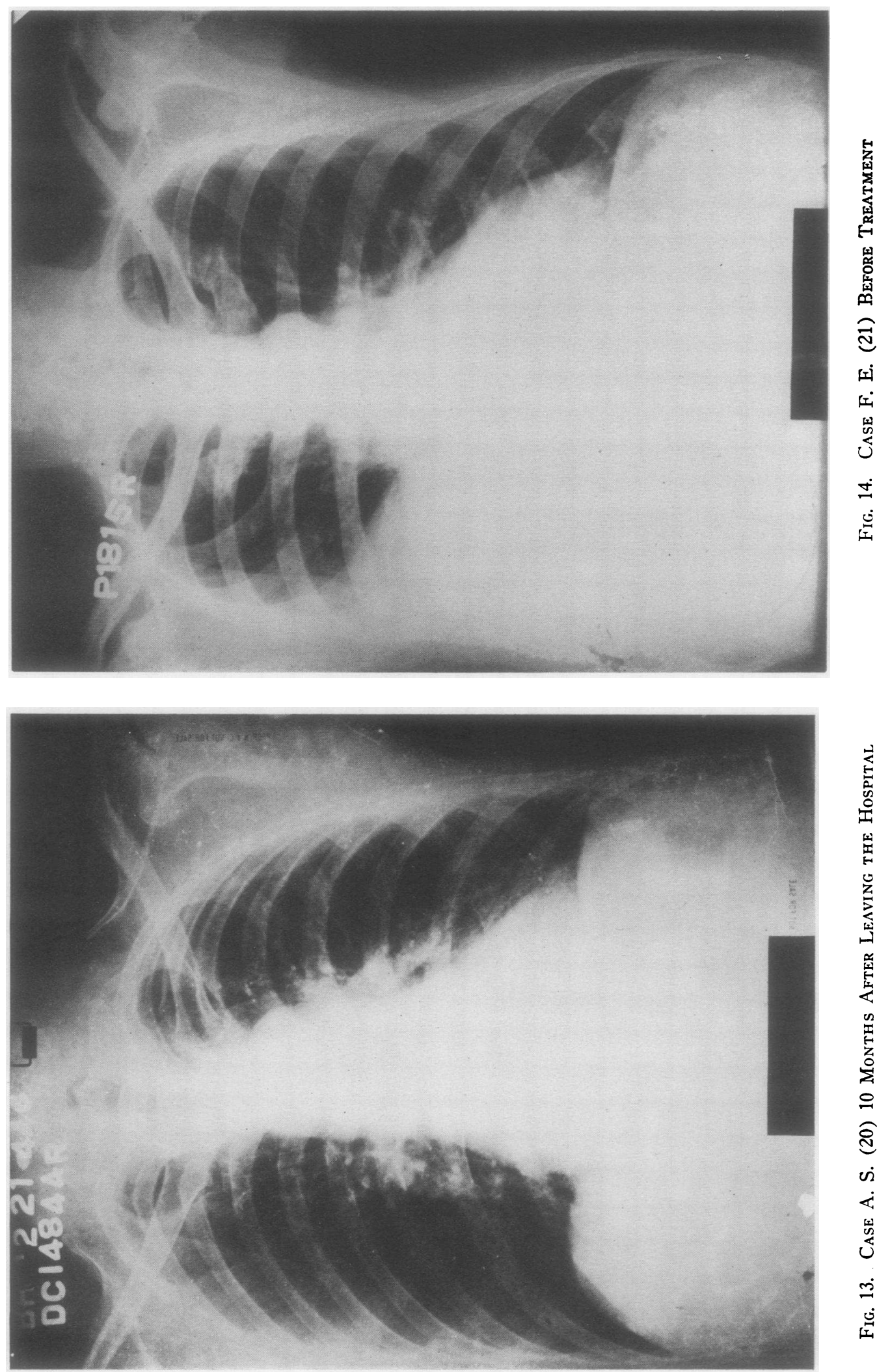


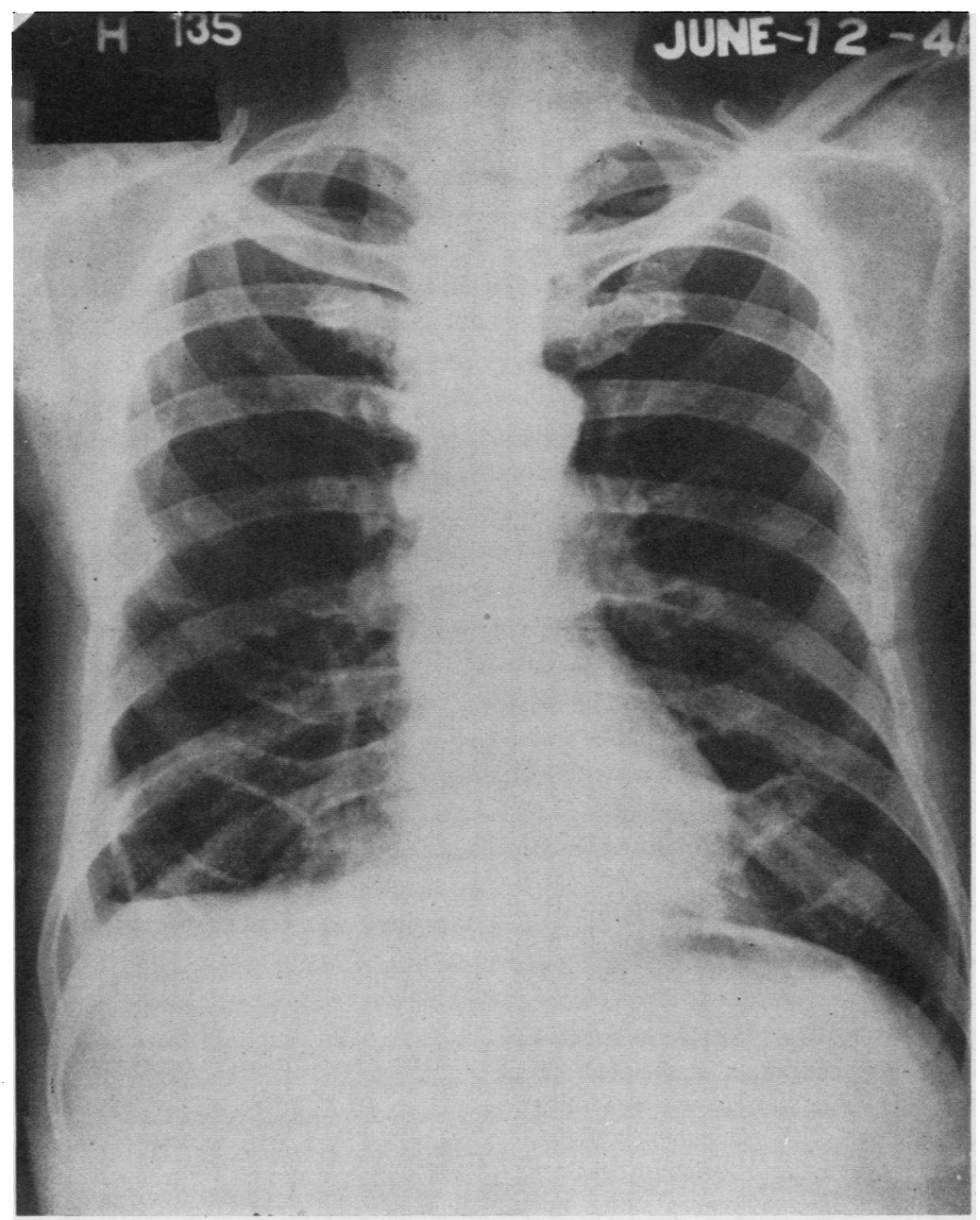

Fig. 15. Case F. E. (21) One Month After. Leaving the Hospital *

* X-ray photograph of this figure was taken at the Home for Dependents, Welfare Island, N. Y., and is reproduced through the courtesy of the authorities of the Hospital (Dr. Maxwell Lewis, Supt.).

taken into account in formulating the most favorable therapeutic procedure with respect to the usefulness or limitations of penicillin. The findings recorded in this article suggest that exudates (pneumococcal) sterilized by penicillin and contained within a closed serous cavity present circumstances which are in many respects unique.

A tentative analysis of some of the special factors may be outlined as follows: When the viable pneumococci are destroyed by penicillin, the stimulus for the migration of leukocytes is considerably lessened and the remaining sterile exudate gradually assumes an acellular character. With the marked reduction in leukocytes, the resolving process is, in part, deprived of one of its important constituents (proteolytic enzymes). The gross appearance of the exudate accordingly changes only to a limited degree as the clearing of the lesion gradually progresses.

The somewhat protracted rate of absorption from the pleural cavity appears to be dependent upon factors involving the degree of oncotic pressure of the exudate in relation to its relatively high concentration of protein within the pleural cavity. Alterations in the absorbing surface of the affected pleura that are dependent on the presence of an exudative coating also require consideration. 
Finally, the limitations in the development of fibrous tissue at the site of the infection suggest that the stimuli for fibroblastic reproduction derived from sterile exudates of pneumococcal origin are restricted in degree by comparison with the effect of certain other infections that are characterized by extensive local tissue necrosis.

Specific experimental studies concerning the problems just mentioned are now in progress.

\section{COMMENTS ON INDIVIDUAL CASES}

Two of the patients have had subsequent attacks of lobar pneumonia due to pneumococci of a serological type different from that causing the initial pneumonia and empyema. The infection involved the same lobe as that of the first infection. Empyema did not develop.

Casc T. C. (No. 5 in Table I). The first attack which was complicated by empyema consisted of pneumonia and bacteremia due to pneumococcus, Type I. The second attack of pneumonia occurred while the patient was still in the hospital in the latter convalescent stages of empyema. There was a sudden rise in fever with thoracic pain and rusty sputum. Pneumococcus, Type III, was isolated from his sputum. No bacteremia was present. The response to intravenous injections of penicillin was prompt. There was no reaccumulation of pleural effusion, although the lobar involvement was the same in each attack.

Case A. S. (No. 20 in Table I). The first attack of pneumonia with which empyema was associated was caused by pneumococcus, Type XIX. He was readmitted to the hospital 5 months later with pneumonia and bacteremia, pneumococcus, Type I, and delirium tremens following an alcoholic spree. Recovery was satisfactory following intravenous penicillin therapy. No effusion dereloped in the affected side.

\section{A case which later developed osteomyclitis}

Case R. C. (No. 4 in Table I). The patient was an 8-year-old boy whose empyema was caused by pneumococcus, Type I. Just before the time for discharge from the hospital, he suddenly developed a high fever which proved to be due to osteomyelitis of the right femur. Pneumococci were not isolated from the blood or infected bone. The case had the usual characteristics of acute staphylococcal osteomyelitis. Surgical drainage and penicillin therapy were employed. There was no involvement of lungs or pleura.

\section{Trwo patients had pulmonary tuberculosis}

Case R. M. (No. 15 in Table I). Female, age 23 years. Tuberculosis had been present for 9 years. There had been wide spread involvement of both lungs. Previous $\mathbf{x}$-rays had revealed extensive calcification involving particularly the right pleura, which was the site of the pneumococcal empyema. At the time she developed pneu- monia, the tuberculosis was well controlled although not entirely inactive.

In the treatment of her pneumococcal empyema, she received a total of 5 injections of penicillin. (One dose of 25,000 units and 4 doses of 30,000 units.) Pneumococci were not recovered from any of the samples of exudate taken after the first dose of penicillin had been injected. The clinical course of the empyema was not different from that of the other patients, except that a thin layer of serous effusion has persisted from which tubercle bacilli have been recovered. Her general condition is considered to be good.

Casc G. B. (No. 18 in Table I). Colored, male, age 22 years. The patient has had pulmonary tuberculosis for 6 years. During the past 2 years, he has been treated with artificial pneumothorax, repeatedly induced.

He developed pneumonia at a time when pneumothorax was present. Pyopneumothorax ensued due to pneumococcus, Type XVIII.

Pneumococci have not been recovered from the pleural effusion at any time since the first injection of penicillin. He received 4 injections of penicillin of 50,000 units each.

The pneumothorax persisted and the effusion continued to reform although its character gradually changed over a period of 6 weeks from thick, purulent material to a somewhat thinner sanguinous effusion.

In view of the fact that the partially collapsed uberculous lung was unable to expand, a thoracoplasty was performed 3 months after the pneumococcal empyema had subsided.

\section{A case complicated by marked arteriosclerosis and scnility}

Case F. E. (No. 21 in Table I). White, male, age 71 years. There was widespread arteriosclerosis and cerebral degeneration. The patient was disoriented and uncooperative.

His course did not differ from that of the others except that an intermittent fever persisted for 18 days after treatment was stopped. When he became afebrile he was transferred to another institution for custodial care. His final $\mathrm{x}$-ray which shows almost complete clearing is presented.

\section{In two cases the empyema a'as associated with a broncho-} pleural fistula

Case M.W. (No. 6 in Table I). White, male, age 50 years. Before admission, the patient had suffered from an acute respiratory infection for 5 weeks. Because of the concomitant occurrence of copious purulent sputum and a thick pleural effusion, he was considered to have had a bronchopleural fistula. On admission, he was not acutely ill, his temperature ranged from $99^{\circ}$ to $100^{\circ} \mathrm{F}$. and the broncho-pleural opening had sealed off as indicated by the absence of cough or sputum.

A small pocket containing $15 \mathrm{ml}$. of thick pus was found which containued Type I pneumococci.

A single injection of 25,000 units of penicillin proved sufficient to eradicate the infection and on only one subse- 
quent occasion could fluid be obtained by aspiration. The patient progressed to complete recovery.

Case C. G. (No. 19P in Table I). White, female, age 27 years. This patient was reported in detail in the former article (1). Her diagnosis was pyopneumothorax. Pneumococcus, Type XIX, and $H$. influenzae were isolated from the pus.

The pyothorax cleared following intrapleural therapy with penicillin. However, the pneumothorax persisted and increased so that there was almost complete collapse of the right lung. She was discharged from the hospital afebrile and has been observed for the past year both on our Service and on the Chest Service of Bellevue Hospital.

Her right lung has gradually expanded until it has reached the thoracic wall except at the site of a small circumscribed effusion. Because of the excellence of the patient's general health no attempt has been made to aspirate the small effusion.

\section{$A$ patient who left the hospital while a large sterile} pleural effusion was still present

Case R. E. (No. 13 in Table I). Colored, male, age 37 years. Intrapleural penicillin therapy was begun on the 16th day following the beginning of pneumonia due to pneumococcus, Type VIII. He received 50,000 units on each of 3 alternate days. Cultures were sterile after the first treatment.

An interesting feature of this case was the reaccumulation of large amounts of sterile pus. On 8 occasions after treatment was discontinued, amounts of exudate ranging from 250 to $375 \mathrm{ml}$. were drained off by thoracentesis.

His general health was very good during the latter period, he was ambulatory, and gained $10 \mathrm{lbs}$. in weight in 3 weeks.

He left the hospital against advice on the 34th hospital day while an effusion of considerable size was still present. He was seen subsequently 6 months after discharge. According to his history, he had resumed work as a janitor a few days after going home and had worked continuously.

An x-ray taken after the 6 months' interval (see $\mathrm{x}$-ray) showed limited lateral thickening of the pleura without any residue of effusion being present.

In retrospect, the satisfactory course which this patient pursued brings into question the advantages that may be derived from repetitions of the aspirations after sterilization has been accomplished.

\section{SUM MARY}

The results obtained in the treatment of 21 cases of pneumococcal empyema by intrapleural injection of penicillin may be summarized as follows :

Twenty of the cases recovered without evidence of residual chronic infection or thoracic deformity or a detectable reduction in pulmonary function.
In 14 of them, a single series of local injections ranging from 1 to 5 doses given on alternate days proved sufficient.

In 7, relapses occurred when the initial course of treatment was suspended.

The reinstitution of local treatment with penicillin resulted in permanent clearing of the infection in 6 of the cases with recurrence.

Although the recurrences protracted the duration of the illness, the completeness of ultimate recovery was not impaired. The single unsuccessful case was a child of 2 years of age who was operated upon when the early treatment was followed by a relapse.

Two patients had low-grade active pulmonary tuberculosis of long standing on which pneumonia and empyema were superimposed. The pneumococcal infection of the pleura responded to the treatment in a manner similar to the other patients but the tuberculous infection remained unimproved.

The patients as a group have been followed in most instances for several months after discharge from the hospital. The clearing of the sterile deposits of exudation on the pleural surfaces, as determined by the $x$-ray examinations, required from 3 to 9 weeks. However, the period during which it was possible to obtain free fluid by aspiration was considerably shorter. Adopting as a measure of the duration of disease under penicillin therapy, the interval between the first and last successful thoracenteses, the average time was 24 days.

The general health of the patients during the post-therapeutic period of resolution was satisfactory. The usual manifestations of suppuration improved considerably in advance of the actual disappearance of the sterilized exudate.

The ultimate outcome has been characterized by the return of the affected side to essentially a normal functional state. The residual anatomical abnormalities, as illustrated by the accompanying $\mathrm{x}$-ray photographs, indicates the limited degree of pleural thickening which has remained.

The method of treatment has, for the most part, consisted of injections of from 25,000 to 50,000 units of penicillin on alternate days for a minimum of 3 doses. The amount of the individual doses of penicillin and the duration of treatment 
have been varied from the prescribed course according to special circumstances presented by individual cases with respect to extent of the involvement and the general condition of the patient.

Special factors that appear to be involved in the process of recovery have been discussed.

Two of the patients in the Pediatric age group $(\mathrm{Pa}-$ tients E. F. (3P) and M. J. (17P) of Table I) were treated with the permission of Dr. James Wilson, Director of the Pediatric Service of Bellevue Hospital. The third pediatric patient (Patient R. C. (4) of Table I) was treated with the permission of Dr. C. W. Lester and Dr. Fenwick Beekman, Chief of the Surgical Pediatric Service of Bellevue Hospital.

Data with regard to the pre- and post-empyema course of the 2 patients with tuberculosis are presented with the permission of Dr. J. B. Amberson, Director of the Chest Service of Bellevue Hospital.

\section{BIBLIOGRAPHY}

1. Tillett, W. S., Cambier, M. J., and McCormack, J. E., The treatment of lobar pneumonia and pneumococcal empyema with penicillin. Bull. New York Acad. Med., 1944, 20, 142.

2. Butler, E. C. B., Perry, K. M. A., and Valentine, F. C. O., The treatment of acute empyema with penicillin. Brit. M. J., 1944, 2, 171 